\title{
Specification of sediment maintenance flows for a large gravel-bed river
}

\author{
Peter R. Wilcock \\ Department of Geography and Environmental Engineering, The Johns Hopkins University, Baltimore, Maryland \\ G. Mathias Kondolf, and W. V. Graham Matthews \\ Center for Environmental Design Research, University of California, Berkeley
}

\author{
Alan F. Barta \\ Intermountain Research Station, U.S. Forest Service, Boise, Idaho
}

\begin{abstract}
Reservoir releases may be specified to flush interstitial fine sediment from gravel beds in the river downstream. Choice of an effective flow depends on trade-offs among discharge, flow duration, and pool dredging as they determine rates of bed mobilization, sand removal, and gravel loss. A basis for evaluating these trade-offs is developed with an approximate method appropriate to the sparse data typically available. Sand and gravel transport are represented with rating curves. Approximate methods are introduced for estimating effective gravel entrainment, subsurface sand supply, and pool sediment trapping. These are combined in a sand routing algorithm to evaluate flushing alternatives for the Trinity River, California. A sediment maintenance flow of moderate size, just sufficient to entrain the bed surface over the duration of the release, limits gravel loss and maximizes sand trapping by pools. Larger discharges produce more fines removal but at the cost of greater gravel loss and reduced selective transport of fines. Dredged pools increase sand removal efficiency by providing multiple exits from the channel and minimize gravel loss if dredged sediment is screened and gravel returned to the river.
\end{abstract}

\section{Introduction}

River channels immediately downstream of reservoirs typically experience a decrease in flood magnitude and sediment transport capacity; if flow diversions are made at the reservoir, total discharge is also reduced. Supply of coarse sediment to the downstream channel is typically eliminated by trapping at the reservoir, whereas fine sediments may be introduced to the downstream channel either from the reservoir or from downstream tributaries. If the transport capacity of the downstream channel is sufficiently reduced, the finer sediment may accumulate on the bed of the river. Controlled releases of reservoir water can be used to mimic the action of natural floods in removing accumulated fine sediments from the channel and loosening the gravel bed. Such a sediment-maintenance flushing flow is similar to, but typically smaller than, a channelmaintenance flow intended to maintain erosion and depositional processes throughout the channel and floodplain [Hill et al., 1991; Ligon et al., 1995; Milhous, 1982; Reiser et al., 1989]. The two types of flushing flow are broadly complementary, although their specific objectives may conflict.

Flushing flows are frequently specified to restore or maintain aquatic habitat, especially for salmonids (salmon and trout). Because the ecological response to both reservoir operations and flushing flows is complex, dependent on external factors, and often evident only over periods of years or decades, the goals of flushing flows are most usefully stated in

Copyright 1996 by the American Geophysical Union.

Paper number 96WR01627.

0043-1397/96/96WR-01627\$09.00 terms of measurable changes to the physical habitat that may be produced by a flushing release, rather than the abundance of organisms [Ligon et al., 1995; Kondolf and Wilcock, 1996]. Flushing flow goals include removing fine sediment from pools used for rearing habitat and from gravel and cobble substrates used for spawning, juvenile cover, and invertebrate food production. A flushing release may also be needed to entrain coarse sediment on the bed surface, permitting removal of subsurface fine sediment and producing a looser structure that facilitates salmonid redd construction [Beschta and Jackson, 1979; Milhous, 1990; Diplas and Parker, 1985]. Entrainment of sediment throughout the active channel section may be specified to prevent establishment of mature vegetation within the active channel, with a corresponding loss in aquatic habitat and channel capacity [Kondolf and Wilcock, 1996]. Erosion of the river banks and floodplain may be desirable to maintain topographic diversity and provide a supply of coarse sediment [ $\mathrm{Li}$ gon et al., 1995].

There is a clear need to specify flushing flows as accurately as possible. Released water is typically not available for storage, diversion, and power generation, so the financial cost of a flushing flow can be very large. Because the rate and efficiency of sand removal increase with discharge $Q$, cost constraints suggest that $Q$ should be as large as possible. The rate of gravel transport increases with $Q$, typically more rapidly than that for sand, and a flushing flow can produce a net decrease of gravel in the channel if gravel supply is limited by reservoir trapping. Because gravel is an important component of fluvial habitat, gravel loss, or its artificial replacement, represents an environmental and financial cost of flushing flows that argues for a flushing $Q$ that is a small as possible. A minimum $Q$ may be set 


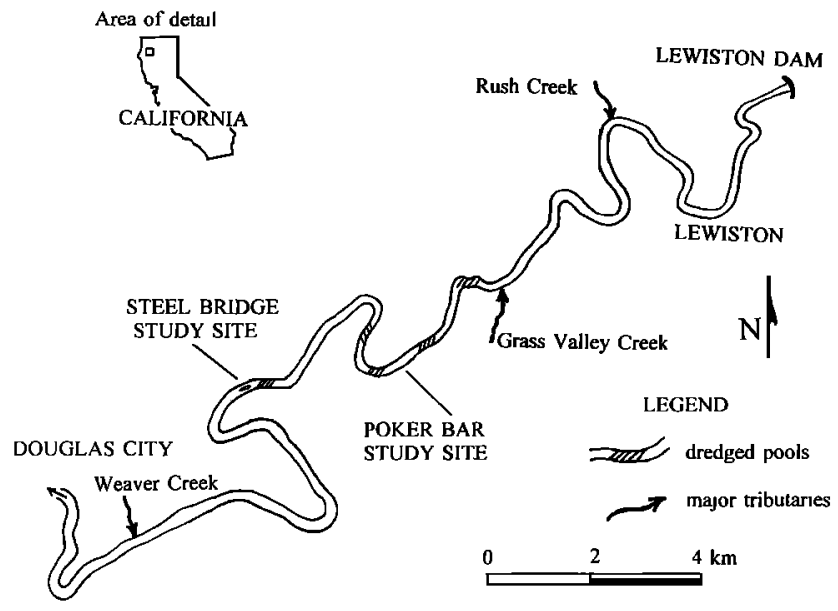

Figure 1. Location map. Flushing estimate prepared for reach from Grass Valley Creek to Steelbridge. Sand routing uses subreaches bounded by the major pools.

by the need to entrain the gravel on the bed surface in order to remove fine sediment from the bed subsurface and loosen the gravel bed.

The size of a flushing flow may also be constrained by the release capacity at the dam, the financial and legal liability associated with an artificial flood, and the availability of water at the appropriate time. Moreover, transport observations in both the field and the laboratory suggest that only a narrow range of flow produces entrainment of most of the bed surface (allowing gravel loosening and subsurface sand removal), while maintaining the selective transport of fine sediment necessary to reduce the fines content of the bed [Wilcock, 1995]. The various goals and constraints for flushing flows impose both minimum and maximum constraints, suggesting that the range of effective flushing flows may be quite narrow.

Accurate specification of flushing flows is hampered by the complexity of the flow and transport system and the sparse data typically available. Both problems arise from the large scale of river reach typically considered, the spatial and temporal variability in flow and transport within the reach, and the nonlinear nature of the flow-sediment interaction. At the reach scale, transport estimates are typically made with highly simplified models; field calibration using spot observations is necessary for any useful accuracy. The trade-off between model accuracy and data availability is of immediate concern in this paper, because the need exists for flushing flow estimates that are both efficient (requiring a minimum of observation) and sufficiently accurate to permit evaluation of different flushing alternatives.

In view of the difficulties involved in accurately specifying a flushing flow, it is not surprising that flushing flows are often prescribed using broad rules based on simple analogy. The most common approach is to specify a flow whose frequency is that observed (or assumed) to produce desirable flow and transport conditions on other channels. For example, a discharge with a prescribed recurrence interval (e.g., 2 years, based on the prereservoir hydrologic record) may be prescribed because such floods have been taken to correlate, on average, with channel-forming conditions of flow and transport in self-adjusted channels [e.g., Leopold et al., 1964; Andrews, 1980]. Such a rule, however, represents only the mean behavior of many channels and cannot be applied to any particular site with confidence. More importantly, the analogy depends critically on the assumption that each channel has adjusted to a steady state geometry for the water and sediment supplied to it. This assumption is not likely to hold for channels downstream of existing reservoirs, for which the water and sediment supply have been altered.

Specification of the magnitude, duration, and timing of a flushing flow requires defining quantifiably achievable objectives, developing a set of simple, but representative, functions representing gravel and sand transport and sediment trapping by pools, and combining these functions in a sediment routing algorithm, so that the trade-offs among different flushing options can be evaluated. A method for evaluating flushing flow options is developed in this paper for the Trinity River in northern California. Although developed for a particular river, we believe these methods have application to other sites, not for the merits of any individual step, many of which are obvious approximations of more complete treatments, but for the manner in which the steps, in combination, permit a quantitative evaluation of the different flushing options that is appropriate to the level of data typically available.

\section{History of Channel Change on the Trinity River}

The Trinity River drains $7640 \mathrm{~km}^{2}$ of steep terrain in the Klamath Mountains of northwestern California (Figure 1). Runoff from the uppermost $1860 \mathrm{~km}^{2}$ of the basin was impounded by Trinity Dam (and its reregulating reservoir, Lewiston Dam) beginning in 1961, as part of the U.S. Bureau of Reclamation Central Valley project. From 1963 to 1995 , about $75 \%$ of the average natural runoff of $47 \mathrm{~m}^{3} / \mathrm{s}$ from the upper basin has been exported via a series of hydroelectric plants to the Sacramento River basin, where it is diverted for irrigation. Floods have been virtually eliminated on the Trinity River in the reach directly below the reservoir. Flow regulation has reduced the mean annual flood $Q_{\text {ma }}$ from 525 to $73 \mathrm{~m}^{3} / \mathrm{s}$ and the 2-year flood $Q_{2}$ from 484 to $30 \mathrm{~m}^{3} / \mathrm{s}$, based on the continuous discharge record from 1911 at the U.S. Geological Survey (USGS) gage at Lewiston (Figure 2). In the 35 years following dam closure, the largest single daily mean discharge $Q$ has been $391 \mathrm{~m}^{3} / \mathrm{s}$, and there have been only 13 days with $Q>240 \mathrm{~m}^{3} / \mathrm{s}$, which is one-half the predam 2-year flood.

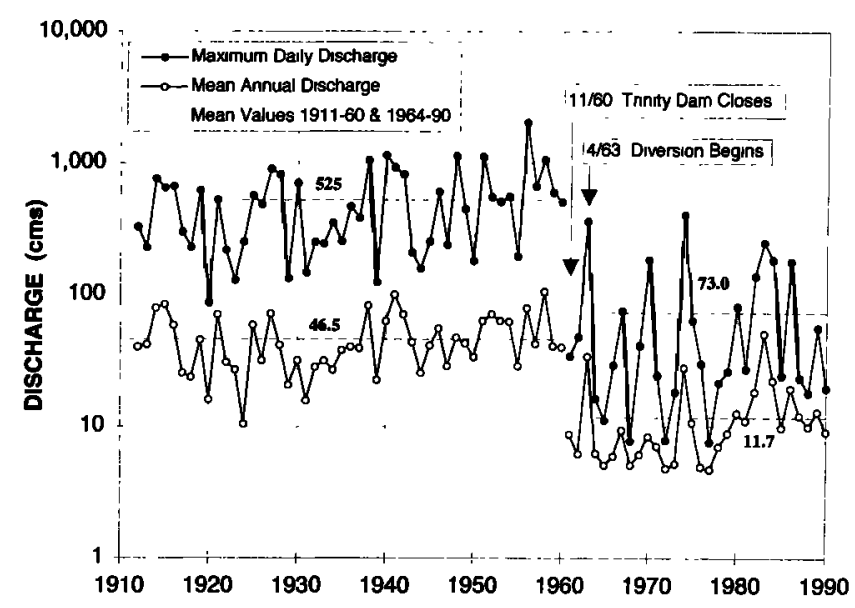

Figure 2. Mean annual discharge and annual maximum daily discharge, USGS gage, Trinity River at Lewiston, 1911-1990. 
Concurrent with the reduction of sediment transport capacity in the mainstem, sediment yields from tributary watersheds increased as a result of road construction and timber harvest. Most notable among these tributaries is Grass Valley Creek, which flows into the Trinity River about $13 \mathrm{~km}$ downstream of Lewiston Dam (Figure 1). Grass Valley Creek drains a $98 \mathrm{~km}^{2}$ basin underlain principally by the Shasta Bally Batholith, which weathers to produce decomposed granitic soils that are readily eroded and produce large yields of sediment finer than $8 \mathrm{~mm}$. From 1950 to $1960,90 \%$ of the Grass Valley Creek basin was logged, resulting in estimated annual sediment yields of $102,000 \mathrm{~m}^{3}$ in the 1970s [Frederiksen, Kamine, and Associates, 1980].

The primary postdam changes to the Trinity River channel have resulted from deposition of tributary-derived sediments within the channel bed and in steep, fine-grained banks along the channel margins. Although the sediment in both deposits comes from the same tributary source, there is little overlap in grain size: fine sediment within the channel bed is predominantly $1 \mathrm{~mm}$ to $8 \mathrm{~mm}$ in size, whereas the bank sediments are predominantly finer than $1 \mathrm{~mm}$ (J. Pitlick, personal communication, January 1995). Little transport of bed material occurs at $Q<85 \mathrm{~m}^{3} / \mathrm{s}$, and essentially no transport of material coarser than $1 \mathrm{~mm}$ occurs at the typical postdam in-stream minimum flows of $4 \mathrm{~m}^{3} / \mathrm{s}$ (1961-1978) and $8.5 \mathrm{~m}^{3} / \mathrm{s}$ (1978 to present).

The absence of sediment finer than $1 \mathrm{~mm}$ in the channel bed suggests that most, if not all, main stem flows are capable of preventing its deposition on the bed and that much of this sediment is transported directly through the reach. Some deposition of this sediment does occur in low-velocity overbank regions under favorable depositional conditions of high river stage and high sediment concentration. Encroachment of riparian vegetation within the predam active channel plays a central role in this bank building by slowing the overbank flow, inducing deposition of suspended sediment, and stabilizing the banks. These banks have narrowed the channel to $20-60 \%$ of its predam width, producing a straightened channel course with decreased topographic variability. The bank deposits are now anchored by mature riparian vegetation (principally alder and willow) and cannot be removed by the largest likely reservoir release of $240 \mathrm{~m}^{3} / \mathrm{s}$, which is the legally recognized postdam 100-year flood. Thus bank removal cannot be accomplished by flushing flows on the Trinity River. However, the controls of bank deposition do influence the timing of flushing flows, if they are to not cause further bank building.

High flow releases from Trinity Dam contain little sediment and have typically lagged behind tributary peak flows, which are the principal postdam source of suspended sediment. Thus most postdam high flows are unlikely to have contributed to aggradation of the inset banks. Our analysis of water and sediment records for USGS gages in the Trinity and adjacent basins for the 35-year period after dam closure (1961-1995) indicates that of the 208 days for which main stem flows have exceeded $85 \mathrm{~m}^{3} / \mathrm{s}$ (the threshold for nonnegligible transport of the channel bed), only 46 days have coincided with large rates of tributary sediment supply (defined as runoff exceeding 10 $\mathrm{mm} / \mathrm{d}$, which is the runoff associated with $81 \%$ of the total suspended sediment yield from Grass Valley Creek over a 15-year period). Of these 46 days, 3 days in 1974 and 6 days in 1983 had exceptionally large tributary floods (62\% of the total sediment yield for the 15-year record on Grass Valley Creek was delivered during the 6 days in 1983). Thus deposition of the inset fine-grained banks of the present river channel ap- pears to have occurred over a cumulative duration of the order of only one to several weeks. This rapid deposition imposes an important constraint on the timing of flushing releases for in-channel sediment maintenance: future flushing releases should be timed to avoid tributary floods in order to minimize further bank deposition and loss of within-channel topographic diversity.

\section{Flushing Objectives and Options}

Different flushing objectives may be defined for the fine and coarse portions of the bed material. One clear objective is to remove as much sand as possible. When the value of the water is considered, a related objective is to minimize the volume of water used or to maximize the sand removal per volume of water. For the gravel, one objective is to entrain the bed surface in order to permit removal of subsurface sand and to maintain some looseness in the bed structure. Because reservoir trapping has severely reduced the supply of new gravel to the reach, a flushing release should also produce a minimum of downstream gravel transport to limit gravel loss. Further, because the ratio of sand to gravel transport increases with decreasing discharge, a smaller discharge produces stronger selective removal of sand. The net result is a flushing release that is tightly defined: it should be no larger than that just sufficient to cause entrainment of most of the bed surface, thereby permitting gravel loosening, subsurface flushing, and selective sand transport, while minimizing downstream gravel loss.

The available flow options are the volume of water used and the rate at which it is released. A third option, dredging pools to act as sediment traps, is also considered because sand traps can provide a larger and more even distribution of sand removal for a specified volume of water. Further, if the dredged material is screened, transported gravel can be returned to the channel, which directly increases the selective removal of sand and may allow larger, more efficient sand-removal discharges to be used.

There is no combination of release volume and discharge that optimizes all objectives. Some of the objectives evidently conflict. A discharge cannot both minimize gravel transport and maximize sand transport; a release that is just sufficient to produce entrainment of most of the bed surface will maximize neither selective transport nor sand removal efficiency. Because no flushing release can satisfy all flushing objectives, a satisfactory release must be a compromise among the various objectives. Because the relations among release volume, discharge, pool trapping, gravel entrainment, and sediment transport are nonlinear, and in most cases, rapidly varying, quantitative estimates of entrainment and sediment transport are essential in evaluating the trade-offs among the different flushing options.

\section{Methods}

\section{Overview}

Methods for estimating the gravel entrainment, gravel transport, and sand removal during a flushing release necessarily represent a trade-off among system complexity, data limitations, and the need for quantitative estimates of sand and gravel removal. The approach taken here is to use simple functions that represent the essential system response to flushing flows and that can be either directly calibrated using limited field observations or evaluated relative to functions found to be 
broadly applicable in gravel-bed rivers. The basis for evaluating flushing flows is a mass balance of fine sediment in the reach, which requires estimates of an initial quantity of sand and its rate of transport as a function of discharge. Estimates of gravel entrainment and transport rate are necessary to determine the amount of gravel loss and the degree of sand flushing from the bed subsurface. New relations, with limited field calibration, are required to estimate the rate of sediment trapping in dredged pools and sand entrainment from the bed subsurface.

An important and necessary simplification is the treatment of the sediment as a two-part size distribution. This is the minimum necessary to address the objectives of preferentially removing fine-grained sediment. Calculations of sediment transport for a larger number of size fractions require local information on sediment content that is not available. Because the fine sediment forms the matrix of a clast-supported gravel/ cobble bed, it may be argued that it is more transient in content and that it will exhibit transport behavior that differs from the framework gravel and cobbles. This is supported by observations on a wide range of gravel bed rivers [e.g., Carling, 1988; Church et al., 1991; Kuhnle, 1992; Jackson and Beschta, 1982; Leopold, 1992; Lisle, 1995; Wathen et al., 1995]. Such an assumption is also implicit in the basic concept of sediment maintenance flows. Different transport relations are observed for sand and gravel along our study reach of the Trinity River, and the variations in transport rate within the sand and gravel fractions are evidently much smaller than the differences between the two fractions [Wilcock et al., this issue].

\section{Sand Content in Study Reach}

The study reach extends $8.0 \mathrm{~km}$ from the Grass Valley Creek confluence, $13 \mathrm{~km}$ downstream of Lewiston Dam, to the Steelbridge study site (Figure 1). For flushing estimates the reach was divided into five subreaches, separated by major pools. In the study reach, sediment finer than $8 \mathrm{~mm}$ is generally light colored and derived from decomposed granitic terrain, particularly in the Grass Valley Creek watershed. This material comprises $20-30 \%$ of the bed and has a median grain size of $2 \mathrm{~mm}$, with $\sim 75 \%$ in the 1 to $8 \mathrm{~mm}$ range and $90 \%$ coarser than 0.5 $\mathrm{mm}$. Sediment coarser than $8 \mathrm{~mm}$ is predominantly dark colored rock fragments of metamorphic and volcanic origin. The median grain size of the coarse fraction is $36 \mathrm{~mm}$ at Poker Bar study site and $56 \mathrm{~mm}$ at Steelbridge (Figure 1).

The distinct color difference between fine and coarse fractions enabled visual estimates of the proportion of fine sediment $F_{\mathrm{s}}(<8 \mathrm{~mm})$ on the bed surface. Estimates were made at low flow, using the same personnel to avoid systematic downstream bias. For each subreach an approximate estimate of the volume of sediment requiring flushing was developed by mapping regions of uniform $F_{\mathrm{s}}$ on enlarged aerial photographs, from which area-weighted averages were determined. Comparison with pebble counts at the Poker Bar study site suggests \pm 0.1 uncertainty in visual estimates of $F_{\mathrm{s}}$, with slightly greater accuracy for changes in $F_{\text {s }}$ produced by the flushing releases or from reach to reach. Uncertainty in the total volume of sand in each subreach primarily influences the duration or number of flushing releases required to reduce the fines content to a specified level and has a second-order effect on the tradeoffs among flushing alternatives. In practice, regular monitoring is needed to update $F_{\mathrm{s}}$ estimates and flushing recommendations.

A surface layer thickness of $0.075 \mathrm{~m}\left(\approx D_{90}\right.$ of the bed framework gravel) was assumed for the volume of fine sediment on the bed surface that could be flushed with no gravel entrainment. The bed thickness that could be flushed with active gravel entrainment was taken to be $0.15 \mathrm{~m}$, which is slightly larger than the limit of plane-bed gravel scour of 1.7 $D_{90}$ estimated from local observations of gravel entrainment [Wilcock et al., this issue], implying that sand removal can proceed to a depth slightly greater than the depth of gravel entrainment [Beschta and Jackson, 1979; Diplas and Parker, 1985]. A fines content of $25 \%$ was assumed for the subsurface layer, based on the percent finer than $8 \mathrm{~mm}$ observed in bulk samples taken at Poker Bar and Steelbridge.

Sediment trapping in the five major pools along the reach (Figure 1) was measured by surveys before and after trial reservoir releases in 1991, 1992, and 1993. Identical points were surveyed at $1.5-\mathrm{m}$ intervals along networks of parallel cross sections or multiple rays extending from monumented points along the banks. Bed elevation was measured to the nearest $0.025 \mathrm{~m}$ with a fiberglass survey rod. Contour maps were prepared of the bed elevation and the net change in sediment storage in each pool.

\section{Sediment Transport Rates}

Sediment transport rates for sand and gravel are represented using a rating curve

$$
Q_{\imath}=\left(F_{\mathrm{l}} / \alpha_{t}\right)\left(Q-Q_{\mathrm{cl}}\right)^{\beta_{1}}
$$

where the subscript $i$ represents either sand (s) or gravel (g), $Q_{\imath}$ is sediment transport rate in metric tons per day, $F_{\imath}$ is the proportion of sand or gravel on the bed surface, $Q_{\mathrm{ci}}$ is the discharge at the onset of substantial transport, $\alpha_{i}$ and $\beta_{i}$ are fitted coefficients and exponents, respectively, and both $Q$ and $Q_{\mathrm{cg}}$ are in units of $\mathrm{m}^{3} / \mathrm{s}$. The factor $F_{i}$ reduces the transport capacity by the amount of sand or gravel available for transport on the bed surface, which becomes important as a reach becomes flushed of sand and $F_{\mathrm{s}}$ becomes small.

Although the rating curves are obvious simplifications of the actual transport field throughout the reach, they do incorporate dominant features of the process, including a nonlinear increase in transport rate with discharge and the effect of surface concentration on the transport rate of the finer fractions. The rating curves require calibration with field data and are therefore subject to considerable uncertainty arising from the large amount of scatter typically found in measurements of bed load in large rivers. Because flushing results may be sensitive to choice of rating curve, two sets of sediment rating curves are developed to evaluate the sensitivity of the flushing calculations to uncertainty in the estimated transport rates.

One set of rating curves was developed from transport observations made at Poker Bar during trial reservoir releases in 1991, 1992, and 1993 (Figure 1; labeled as Poker Bar in Table 1 and Figure 3 [Wilcock et al., this issue]). The sand rating curve is more sensitive to $F_{i}$ than the gravel rating curve, because the proportional variation in $F_{\mathrm{s}}\left(0<F_{\mathrm{s}}<0.3\right)$ is much larger than that of $F_{\mathrm{g}}\left(0.7<F_{\mathrm{g}}<1.0\right)$. Because $F_{\mathrm{s}}$ varies in both space and time and is generally unknown at the time of sampling, a larger scatter may be expected in the sand transport rates (Figures 3a and 3b). The plotted data and rating curves use a value of $F_{\mathrm{s}}=0.22$, which is a typical value for the Poker Bar subreach. In the sand routing performed later in the paper, $F_{\mathrm{s}}$ varies with both location and time.

The alternative rating curves were selected to provide a fit to both the Poker Bar observations and Helley-Smith bed load samples taken at a discontinued USGS gage at Limekiln, im- 
mediately downstream of our study reach (Figures 3a and 3b). The alternative relations were chosen to provide a clear difference in the ratio of sand to gravel transport upon which the flushing results may depend. The ratio of sand to gravel transport decreases with discharge for both pair of rating curves, with the Poker Bar rating curves decreasing to a value of 0.34 and the alternate curves decreasing to a value of 3.4 at $Q \approx$ $240 \mathrm{~m}^{3} / \mathrm{s}$ (Figure 3d).

Using single rating curves to represent sand and gravel transport throughout the study reach implicitly assumes that transport rates are spatially uniform. Although this clearly cannot be true in detail, the absence of obvious aggradation or degradation within the study reach (as required by strongly nonuniform transport) suggests that the error may fall within acceptable bounds, particularly over entire subreaches for which some of the local error would cancel. A conventional alternative approach, calculating transport rates from sectionaveraged estimates of $\tau_{0}$ from a one-dimensional hydraulic model of the study reach, is likely to give similar or larger errors. Local and section-averaged values of $\tau_{0}$ can be very different, even for reaches and sections with simple geometry [Wilcock et al., this issue]. Because the relation between $\tau_{0}$ and transport rate is strongly nonlinear, particularly at small transport rates, error in $\tau_{0}$ may produce errors in calculated sediment load that are very large and difficult to constrain [Carson and Griffiths, 1987]. For the same reason, this approach is likely to be more sensitive to flow conditions at a limited number of measured cross sections than the rating curve approach used here. Regardless, the information on channel geometry and roughness needed for hydraulic modeling is not available, as is often the case, and an approach using sediment rating curves is likely to be useful at many sites.

\section{Gravel Entrainment}

An estimate of the rate of gravel entrainment is required for two purposes. The first is to determine combinations of $Q$ and flush volume $\forall$ that produce minimum adequate entrainment for bed surface loosening and subsurface flushing. The second is to provide a basis for evaluating the frequency with which subsurface sand is exposed and available for entrainment.

Because of the infrequent and stochastic nature of grain motion at low transport rates, the mobilized proportion of the bed surface will increase with $\forall$ or release duration. The necessary duration for surface entrainment should decrease rapidly with increasing transport rate, but the product of duration and transport rate, transport volume, should vary far less, suggesting that a minimum flush duration for different $Q$ may be approximated using a volume of transported sediment known to provide adequate surface entrainment [Wilcock, 1995].

A reservoir release of $164 \mathrm{~m}^{3} / \mathrm{s}$ for 5 days in 1992 produced nearly complete entrainment of the bed surface [Wilcock et al., this issue]. Using this as a reference combination of $Q$ and $\forall$ for a minimum flushing release, the gravel rating curves may be

Table 1. Parameters for Sediment Rating Curves (1)

\begin{tabular}{llclc}
\hline Rating Curve & $F_{\boldsymbol{t}}$ & $\alpha_{\boldsymbol{\imath}}$ & $\boldsymbol{\beta}_{\boldsymbol{i}}$ & $Q_{\mathrm{c}}, \mathrm{m}^{3} / \mathrm{s}$ \\
\hline Poker Bar gravel & 1.0 & 2,000 & 3.0 & 77 \\
Alternate gravel & 1.0 & 600 & 2.5 & 77 \\
Poker Bar sand & 0.22 & 13.0 & 2.0 & 30 \\
Alternate sand & 0.22 & 350,000 & 4 & 0 \\
\hline
\end{tabular}

$Q_{\imath}$ in metric tons per day, $Q$ and $Q_{\mathrm{ci}}$ in $\mathrm{m}^{3} / \mathrm{s}$.
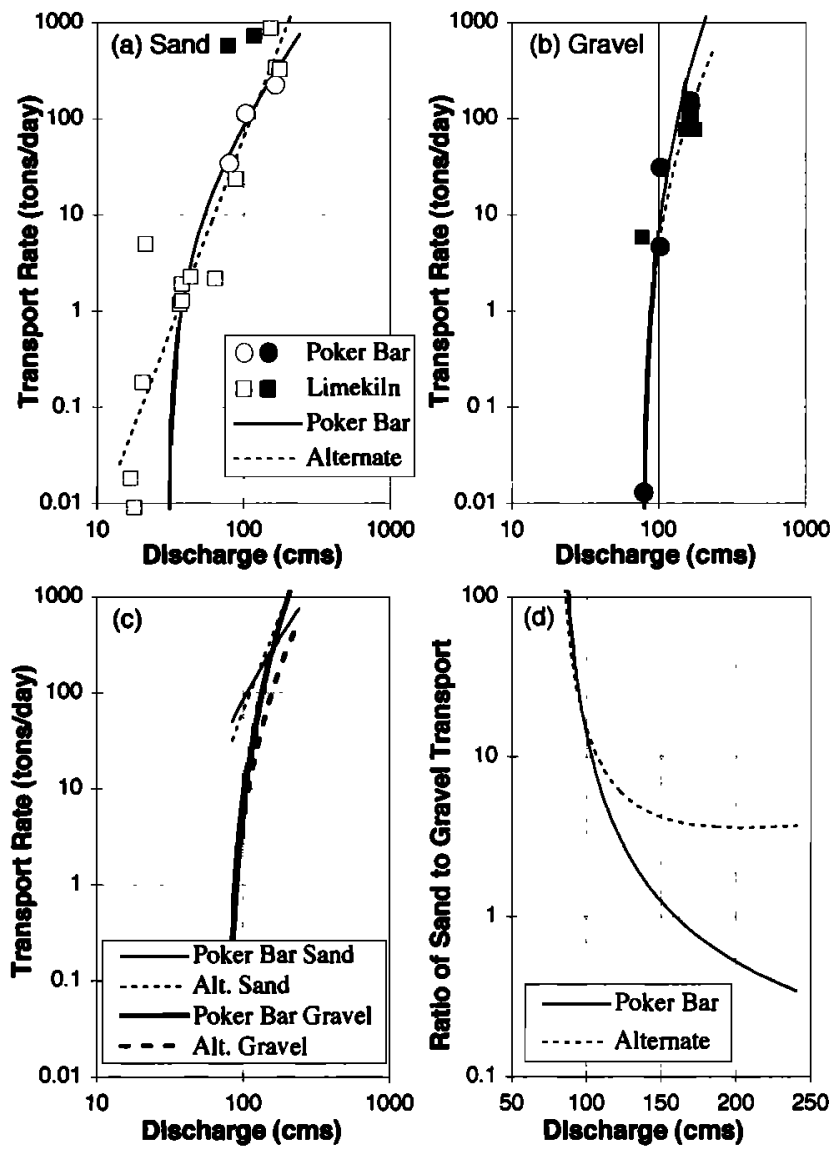

Figure 3. Transport observations and sediment rating curves for sand and gravel. Transport observations from Poker Bar study site and the USGS gage, Trinity River below Limekiln Gulch. (a) Transport of sand ( $<8 \mathrm{~mm}$ ). Transport observations with gray symbols are for $1981 / 1982$, when $F_{s}$ may have been much larger. (b) Transport of gravel $(>8 \mathrm{~mm})$. Gray symbols are transport rates recalculated after excluding the largest and smallest $25 \%$ of samples from the total. (c) Comparison of sediment rating curves for $Q>85 \mathrm{~m}^{3} / \mathrm{s}$. (d) Ratio of sand to gravel transport rates calculated using the Poker Bar and alternative rating curves.

used to calculate other combinations of $Q$ and $\forall$ that produce the same volume of gravel transport. The duration producing minimum satisfactory entrainment, defined here as the exchange time $t_{\mathrm{ex}}$, is assigned a value of 5 days for $Q=164 \mathrm{~m}^{3} / \mathrm{s}$. Using (1), other values of $t_{\mathrm{ex}}$ (in days) are determined for the same transport volume as

$$
t_{\mathrm{ex}}=5\left(\frac{Q_{\mathrm{g}, 92}}{Q_{\mathrm{g}}}\right)=5\left(\frac{Q_{92}-Q_{\mathrm{cg}}}{Q-Q_{\mathrm{cg}}}\right)^{\beta_{\mathrm{g}}}
$$

where $Q_{\mathrm{g}}$ and $Q_{\mathrm{g}, 92}$ are the gravel discharge associated with $Q$ and $Q=164 \mathrm{~m}^{3} / \mathrm{s}$, respectively. Because $\forall=t_{\text {ex }} Q$ and there is a unique value of $t_{\mathrm{ex}}$ for each $Q$, a monotonic relation exists between $\forall$ and $Q$ that represents minimum satisfactory bed entrainment. Equation (2) also provides a timescale that is useful in estimating the upward rate of sand supply from the bed subsurface as a function of gravel entrainment rate.

\section{Pool Trapping}

The storage volume and trap efficiency of each pool must be specified in order to calculate the sand removal that can be 


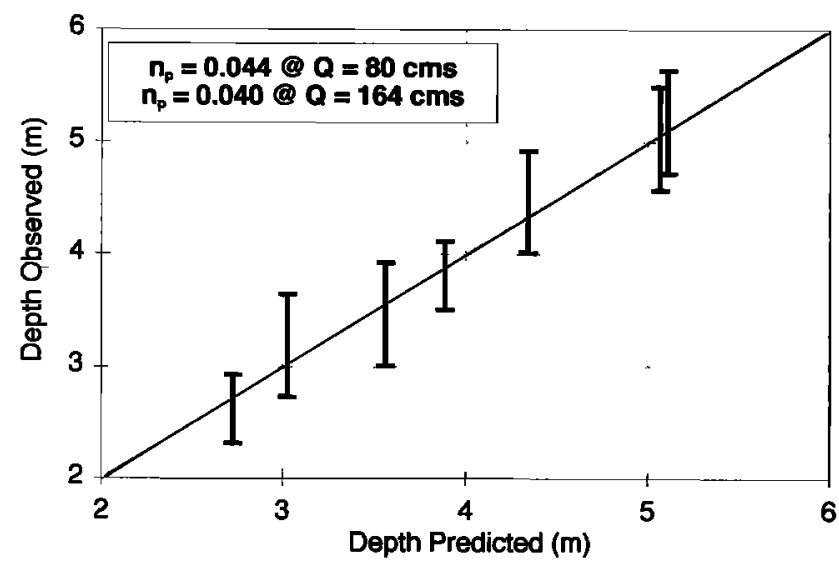

Figure 4. Observed and calculated steady state pool depths. Observed depths based on surveys taken before and after trial releases. Predicted depths from (7) to (11). Best fit is achieved by allowing pool roughness $n_{\mathrm{p}}$ to vary slightly with discharge, although a constant $n_{\mathrm{p}}=0.0415$ provides a trend that falls within the pool depth error bars.

achieved by a flushing release. Because little information is available on the geometry of existing channel/pool reaches and because it is useful to evaluate the utility of adding new pools, for which neither location or configuration are specified, the method used to estimate storage volume and trap efficiency must rely on relatively simple input.

Both scour and fill were observed in dredged pools during the trial releases. In some cases, an individual pool aggraded at one $Q$ and scoured at a higher $Q$. The large settling velocity of the fine bed material $(1-8 \mathrm{~mm})$ and the typical depth and mean velocity in the pools indicate that this sediment moves through the pools as bed load. The observed scour and deposition suggest that a steady state pool depth exists for particular combinations of water discharge, sediment input, and pool geometry. A simple method is developed here to estimate the steady state depth because it provides a useful reference depth for evaluating the relative benefit of different dredging depths in pools of varying width.

Calculation of the steady state pool depth is based on sediment continuity, which requires that the sand transport rate be the same in both channel and pool. To simplify the calculations, the channel is assumed to have a rectangular cross section of width $B_{\mathrm{c}}$ and the pools are rectangular troughs of width $B_{\mathrm{p}}\left(B_{\mathrm{p}} \leq B_{\mathrm{c}}\right)$ and depth $\Delta h$ excavated below the channel bottom. In the upstream channel, discharge $Q$, bed slope $S_{0}$, channel width $B_{\mathrm{c}}$, and channel hydraulic roughness $n_{\mathrm{c}}$ must be specified. For steady, uniform flow, mean channel velocity $U_{\mathrm{c}}$, bed shear velocity $u_{*_{\mathrm{c}}}=\left(\tau_{0} / \rho\right)^{1 / 2}$, hydraulic radius $R_{\mathrm{c}}$, and flow depth $h_{\mathrm{c}}$ are then calculated from water continuity

$$
Q=B h_{c} U_{c}
$$

momentum conservation

$$
u_{* \mathrm{c}}=\sqrt{g R_{\mathrm{c}} S_{\mathrm{c}}}
$$

flow resistance

$$
U_{\mathrm{c}}=\left(1 / n_{\mathrm{c}}\right) R_{\mathrm{c}}^{2 / 3} S_{\mathrm{c}}^{1 / 2}
$$

and the definition of the hydraulic radius

$$
R_{\mathrm{c}}=\frac{B_{\mathrm{c}} h_{\mathrm{c}}}{B_{\mathrm{c}}+2 h_{\mathrm{c}}}
$$

Flow in the pool is assumed to be steady, but nonuniform, so that the simple form of momentum conservation in (4) may not be used and the pool roughness $n_{\mathrm{p}}$ cannot be presumed, although the form of the flow resistance relation is assumed to hold. Sand transport in both channel and pool is assumed to follow the simple proportionality $Q_{\mathrm{s}} \propto F_{\mathrm{s}} u_{*}^{3}$ (equivalent to many transport formulas for transport far in excess of incipient motion). For comparable widths of active transport in the channel and pool, steady state requires that $Q_{\mathrm{s}}$ is a constant. This and the transport relation allow the shear velocity in the pool and channel to be related as

$$
u_{* \mathrm{p}}=\left(F_{\mathrm{s}} / F_{\mathrm{sp}}\right)^{1 / 3} u_{*_{\mathrm{c}}}
$$

where $u_{*_{\mathrm{p}}}$ is the pool shear velocity and $F_{\mathrm{sp}}$ is the surface proportion of sand in the pool. For steady state conditions and specified values of $Q, B_{\mathrm{c}}, B_{\mathrm{p}}, h_{\mathrm{c}}, u_{*_{\mathrm{c}}}, F_{\mathrm{s}}, F_{\mathrm{sp}}$, and $n_{\mathrm{p}}$, it is possible to find $u_{*_{\mathrm{p}}}$ and values of pool velocity $U_{\mathrm{p}}$, crosssection area $A_{\mathrm{p}}$, hydraulic radius $R_{\mathrm{p}}$, and dredge depth $\Delta h$ (difference in bed elevation between channel and pool) from (7), together with continuity

$$
Q=A_{\mathrm{p}} U_{\mathrm{p}}
$$

flow resistance

$$
U_{\mathrm{p}}=\frac{1}{\left(n_{\mathrm{p}} \sqrt{g} R_{\mathrm{p}}^{1 / 6}\right)} u_{* \mathrm{p}}
$$

and the definitions of pool hydraulic radius

$$
R_{\mathrm{p}}=\frac{A_{\mathrm{p}}}{B_{\mathrm{c}}+2\left(\bar{h}_{\mathrm{c}}+\Delta h\right)}
$$

and cross-sectional area

$$
A_{\mathrm{p}}=B_{\mathrm{c}} h_{\mathrm{c}}+B_{\mathrm{p}} \Delta h
$$

For specified $Q, S_{0}, B_{\mathrm{c}}, B_{\mathrm{p}}, n_{\mathrm{c}}, F_{\mathrm{s}}$, and $F_{\mathrm{sp}}$, the only unknown parameter is the pool roughness $n_{\mathrm{p}}$, which is used to match predicted and observed steady state pool depths for trial reservoir releases in 1992 and 1993. Predicted values are calculated using the constant release $Q$, neglecting scour or deposition produced by the relatively short ramping flows at the start and end of each release [Wilcock et al., this issue]. Observed values are determined based on comparison of contour maps of pool bed elevation before and after the releases. To account for incomplete scour or fill during a release, the steady state bed elevation was assumed to fall between the observed final bed elevation and an elevation between $0.5 \mathrm{~m}$ and $1.0 \mathrm{~m}$ lower or higher, depending on whether the pool scoured or filled during the release. Values of $n_{\mathrm{p}}=0.044$ at $Q \approx 80 \mathrm{~m}^{3} / \mathrm{s}$ and $n_{\mathrm{p}}=0.040$ at $Q \approx 164 \mathrm{~m}^{3} / \mathrm{s}$ match the predicted and observed pool depths well (Figure 4). Depths predicted using a constant $n_{\mathrm{p}}=\mathbf{0 . 0 4 1 5}$ also fit within the estimated range of steady state depths for all cases, although the depths are slightly overpredicted at large $Q$ and underpredicted at small $Q$. These values of $n_{\mathrm{p}}$ are somewhat larger than those found for the channel reaches from calibrated flow modeling $\left(n_{\mathrm{c}} \approx\right.$ 0.03 [Wilcock et al., 1995]), which is consistent with the presence of a backwater, as well as dunes, within the pools.

The computational procedure for steady state depth can be modified to calculate the trap efficiency of the pools when $\Delta h$ 
exceeds the steady state depth $\Delta h_{\mathrm{ss}}$. The trap efficiency $T$ is defined as

$$
T \equiv \frac{Q_{\mathrm{sc}}-Q_{\mathrm{sp}}}{Q_{\mathrm{sc}}}
$$

Using the same proportional sand transport relation $Q_{\mathrm{s}} \propto$ $F_{\mathrm{s}} u_{*}^{3},(12)$ may be rearranged as

$$
T=1-\left(F_{\mathrm{sp}} / F_{\mathrm{s}}\right)\left(u_{*_{\mathrm{p}}} / u_{*_{\mathrm{c}}}\right)^{3}
$$

With $\Delta h$ specified, (8)-(11) and (13) may be solved for $T, u_{* \mathrm{p}}$ $U_{\mathrm{p}}, A_{\mathrm{p}}$, and $R_{\mathrm{p}}$. This formulation is used to solve for $T$ in the sand routing calculations.

\section{Sand Supply From the Bed Subsurface}

An expression for the upward supply of sand from the subsurface is needed to account for subsurface flushing during a release. The rate of upward entrainment will depend on the frequency of gravel entrainment from the bed surface, which determines the frequency with which subsurface fine grains are subjected to the flow. Existing formulations are based on the incorporation of subsurface sediments into the active transport layer at a rate proportional to the rate of bed degradation [Ashida and Egashira, 1989; Hirano, 1971; Holly and Rahuel, 1990; Parker and Sutherland, 1990] and therefore cannot represent subsurface entrainment when the rate of degradation is negligibly small or zero. Under these conditions, entrainment of subsurface material may still occur but is limited to finer sizes that may be entrained when a coarser overlying clast is entrained. This appears to be the case on the Trinity River, where little net change in bed elevation was observed during the trial flushing flows. Because an effective flushing flow may often require a compromise between maximizing selective sand transport and minimizing gravel transport, a formulation is needed for estimating subsurface sand entrainment in the presence of small gravel transport rates and negligible change in bed elevation.

In addition to the rate of gravel entrainment, the rate of subsurface sand entrainment depends on the relative concentration of sand in the surface and subsurface. When the two are similar, rates of removal and deposition to the subsurface should also be similar, so that net upward entrainment is likely to be small. When the surface layer is relatively clean of sand, the concentration of sand in transport will be smaller and net entrainment from the subsurface should increase.

The net rate with which sand with mass $M_{\mathrm{u}}$ is removed from the subsurface may be expressed as

$$
\frac{d M i_{\mathrm{u}}}{d t}=\operatorname{const}\left(\frac{\bar{F}_{\mathrm{ss}}-\bar{F}_{\mathrm{s}}}{F_{\mathrm{ss}}}\right) M_{\mathrm{ss}}\left(\frac{1}{t_{\mathrm{ex}}}\right)
$$

where $F_{\mathrm{ss}}$ is the proportion of sand in the subsurface, $M_{\mathrm{ss}}$ is the mass of sand in the subsurface, and $t_{\mathrm{ex}}$ is the exchange time for spatially complete gravel entrainment defined in (2). Values of $t_{\mathrm{ex}}$ vary inversely with $Q$, so that the larger entrainment rates associated with higher discharges produce a smaller $t_{\mathrm{ex}}$ and a more rapid $d M_{\mathrm{u}} / d t$. Because $t_{\mathrm{ex}}$ is a scaled transport volume, $d M_{\mathrm{u}} / d t$ has an inverse linear relation with the volume of gravel transport. The subsurface entrainment rate in (14) depends directly on the relative difference in sand concentration in the surface and subsurface, varying from zero when $F_{\mathrm{ss}}=F_{\mathrm{s}}$ to a constant multiple of $M_{\mathrm{ss}} / t_{\mathrm{ex}}$ when $F_{\mathrm{s}}=0$. When $d t=t_{\mathrm{ex}}$ (e.g., 5 days for $Q=164 \mathrm{~m}^{3} / \mathrm{s}$ ), the mass of sand entrained is a constant proportion of the relative difference in sand mass between the surface and subsurface. For the routing computations discussed below, the value of the constant in (14) is taken to be 0.5 .

\section{Sand Routing Algorithm}

The sand routing algorithm is based on sand mass conservation within the surface layer of the river bed. Sand is routed between subreaches bounded by major pools. Sand output from each subreach is calculated using the sand rating curves (1) (Table 1). Sand input to a subreach is the sum of the output from the next reach upstream, reduced by trapping in the intervening pool, plus the upward sand supply from the bed subsurface (14). The amount of sand trapped in each pool is determined as a function of available depth $h_{\mathrm{d}}$ below the steady state depth $\left(h_{\mathrm{d}}=\Delta h-\Delta h_{\mathrm{ss}}\right)$, which determines the trap efficiency (equations (8)-(11) and (13)) and the remaining storage volume. The mass of sand in the surface and subsurface is recalculated at the end of each time step and used to update values of $F_{\mathrm{s}}$ and $F_{\mathrm{ss}}$. Gravel transport out of each reach is calculated using the gravel rating curves (1) (Table 1). The pools are assumed to trap all gravel when $h_{\mathrm{d}}>0$. Both sand and gravel input to the pools reduce the remaining storage, which is recalculated after each time step. The time step used in all of the calculations discussed here is 1 hour, which is $<1 \%$ of the duration of all simulated releases.

\section{Evaluation of Flush and Dredging Alternatives}

The method developed above is used here to illustrate the trade-offs among discharge $Q$, flush volume $\forall$, sand discharge $Q_{s}$, gravel discharge $Q_{g}$, and pool dredging depth $h_{\mathrm{d}}$ for the study reach of the Trinity River. Although the results are directly applicable only to that reach, some of the underlying trends are likely to be more general, and the presentation illustrates the kind of information necessary for selecting among different flushing options.

Because water costs are often the largest expense in a flushing flow, many of the important trade-offs are evident when flushing results are calculated for a constant $\forall$, which provides an approximate comparison of the relative efficiency of different $Q$ and $h_{\mathrm{d}}$. Figure 5 presents these results for $\forall=1.2 \times 10^{8}$ $\mathrm{m}^{3}$ (100,000 acre feet), which is comparable to the volume used in the 1992 and 1993 trial releases. Figures 5a and 5b present the sand and gravel removed as a function of $Q$ for the Poker Bar and alternate sediment rating curves, respectively. Figures $5 \mathrm{c}$ and $5 \mathrm{~d}$ present the mass of sand trapped in pools for the same values of $Q$. A constant $Q$ is used in the calculations, so the influence of short ramping flows at the start and end of a release is neglected. It is assumed that sediment deposited in pools is removed, screened, and the gravel returned to the channel, so that only sand is removed at pools, whereas both sand and gravel are removed at the downstream end of the reach. Results are shown for dredging the five major pools in the study reach to $h_{\mathrm{d}}=0,0.5,1.0,1.5$, and $2.0 \mathrm{~m}$. For $\forall=$ $1.2 \times 10^{8} \mathrm{~m}^{3}$, the minimum discharge $Q_{\min }$ required to mobilize the bed surface (based on (2); shown as vertical dashed line on Figures $5 \mathrm{a}$ and $5 \mathrm{~b}$ ) is $147 \mathrm{~m}^{3} / \mathrm{s}$ for the Poker Bar rating curves (vertical dashed line on Figures $5 \mathrm{a}$ and $5 \mathrm{~b}$ ) and $143 \mathrm{~m}^{3} / \mathrm{s}$ for the alternate rating curves.

Both sand and gravel removal increase with $Q$ for a constant $\forall$ (Figures 5a and 5b), a result of the nonlinear sediment rating curves. For the same reason, the quantity of sand removed by pools also increases with $Q$ for small $Q$ but reaches a maximum 

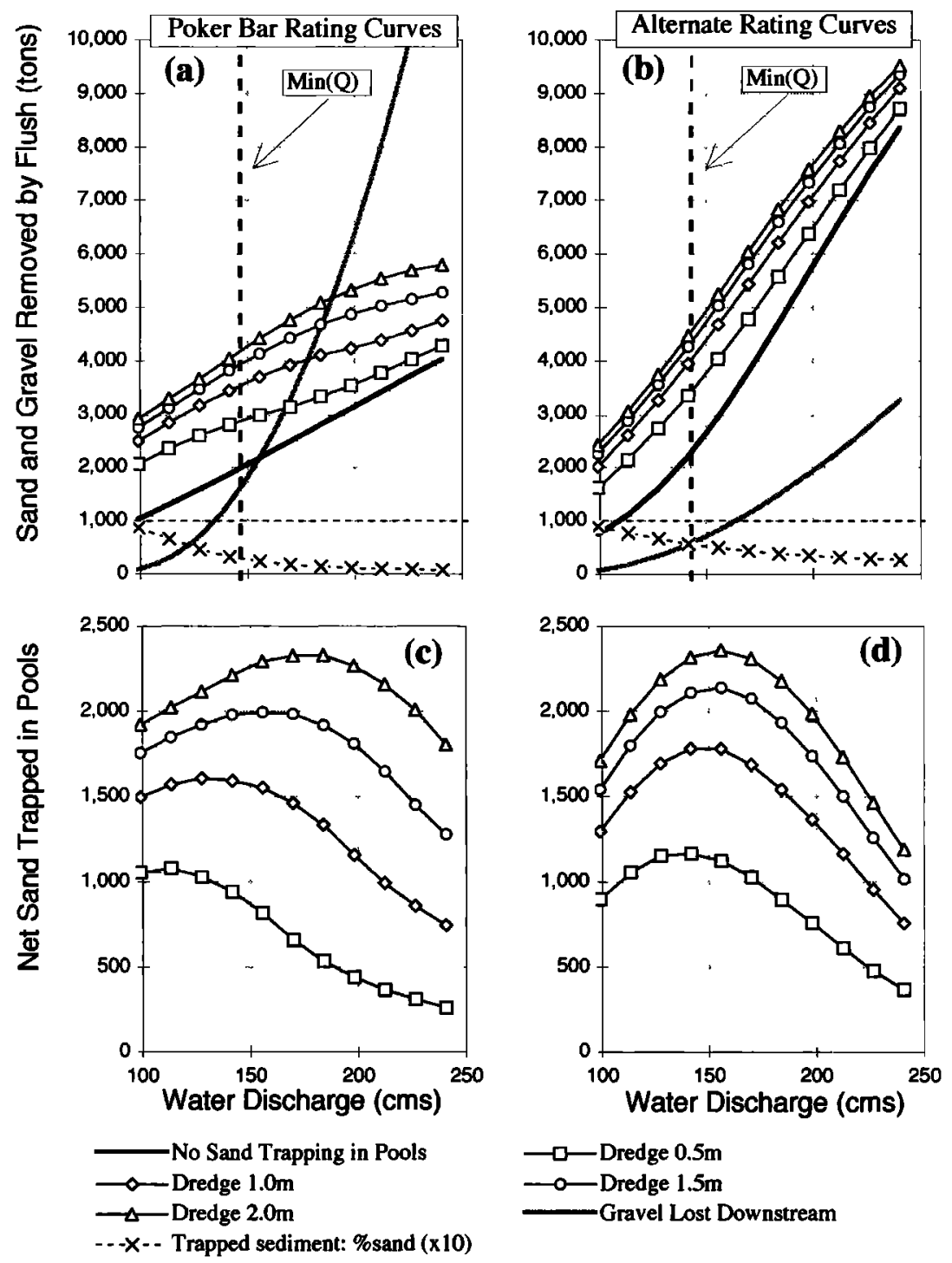

Figure 5. Estimated sand and gravel removed from the study reach using a flush volume of $1.28 \times 10^{8} \mathrm{~m}^{3}$ $(100,000$ acre feet), as a function of discharge and dredge depth in existing pools. (top) Total sand and gravel removed; (bottom) net sand removed by dredged pools. Calculations based on Poker Bar (Figures 5a and 5c) and alternative (Figures $5 \mathrm{~b}$ and $5 \mathrm{~d}$ ) sediment rating curves. $\operatorname{Min}(Q)$ is the minimum constant $Q$ that will entrain the bed surface $\left(t_{\mathrm{ex}}=1\right)$ for the specified water volume. Although the total amount of sand removed increases with $Q$, the amount of gravel lost increases more rapidly and the amount of sand trapped in pools decreases at higher $Q$ because an increasing proportion of pool volume is taken up by gravel.

and decreases with further increases in $Q$ (Figures $5 \mathrm{c}$ and $5 \mathrm{~d}$ ) because pools fill and the proportion of sand (relative to gravel) in the trapped sediment decreases (shown as cross on Figures $5 \mathrm{a}$ and $5 \mathrm{~b}$ ). With either rating curve, a moderate discharge of roughly $150 \mathrm{~m}^{3} / \mathrm{s}$ minimizes gravel loss (subject to the requirement $Q \geq Q_{\mathrm{min}}$ ) and maximizes the quantity of sand trapped in pools. For a given $Q$, additional sand removal may be accomplished with either larger $\forall$ or deeper dredging. The utility of the latter may be judged by the relative separation of the different lines in Figures $5 \mathrm{c}$ and $5 \mathrm{~d}$. For the specified $\forall$ in Figure $5, h_{\mathrm{d}}$ of the order of $1.5-2.0 \mathrm{~m}$ is sufficient to trap most of the sand and larger $h_{\mathrm{d}}$ would not be useful.

The role of $\forall$ in increasing sand removal is shown in Figure 6 , which presents the variation with $\forall$ of the total sand and gravel removed (Figures $6 \mathrm{a}$ and $6 \mathrm{~d}$ ), the efficiency of sand removal (in metric tons of sand per cubic kilometer of water,
Figures $6 \mathrm{~b}$ and $6 \mathrm{e}$ ), and the ratio of sand to gravel removal (Figures 6c and 6f). Figures 6a-6c use a constant $Q=150$ $\mathrm{m}^{3} / \mathrm{s}$; Figures $6 \mathrm{~d}-6 \mathrm{f}$ use $Q_{\text {min }}$, which, for $\forall$ of $0.1,0.2$, and 0.3 $\mathrm{km}^{3}$, are 153,135 , and $126 \mathrm{~m}^{3} / \mathrm{s}$ for the Poker Bar curves and 150,129 , and $120 \mathrm{~m}^{3} / \mathrm{s}$, for the alternative rating curves, respectively. Both cases include dredging to $h_{\mathrm{d}}=0 \mathrm{~m}$ and $1.0 \mathrm{~m}$ in the five existing pools and two new pools $(4100 \mathrm{~m}$ and $5600 \mathrm{~m}$ downstream of Grass Valley Creek) placed in the largest subreach with no existing pools. In all cases, the total volume of sand removed increases with $\forall$, but the efficiency of sand removal decreases with $\forall$ because $F_{\mathrm{s}}$ (and $Q_{\mathrm{s}}$ ) decrease over a longer release and because pools fill with sediment, causing a decrease in trap efficiency. At constant $Q$, reduced sand trapping causes sand removal to increase with $\forall$ less rapidly than gravel loss, causing the sand/gravel removal ratio to decrease with $\forall$ (Figure 6c). For $Q=Q_{\text {min }}$ the volume of 

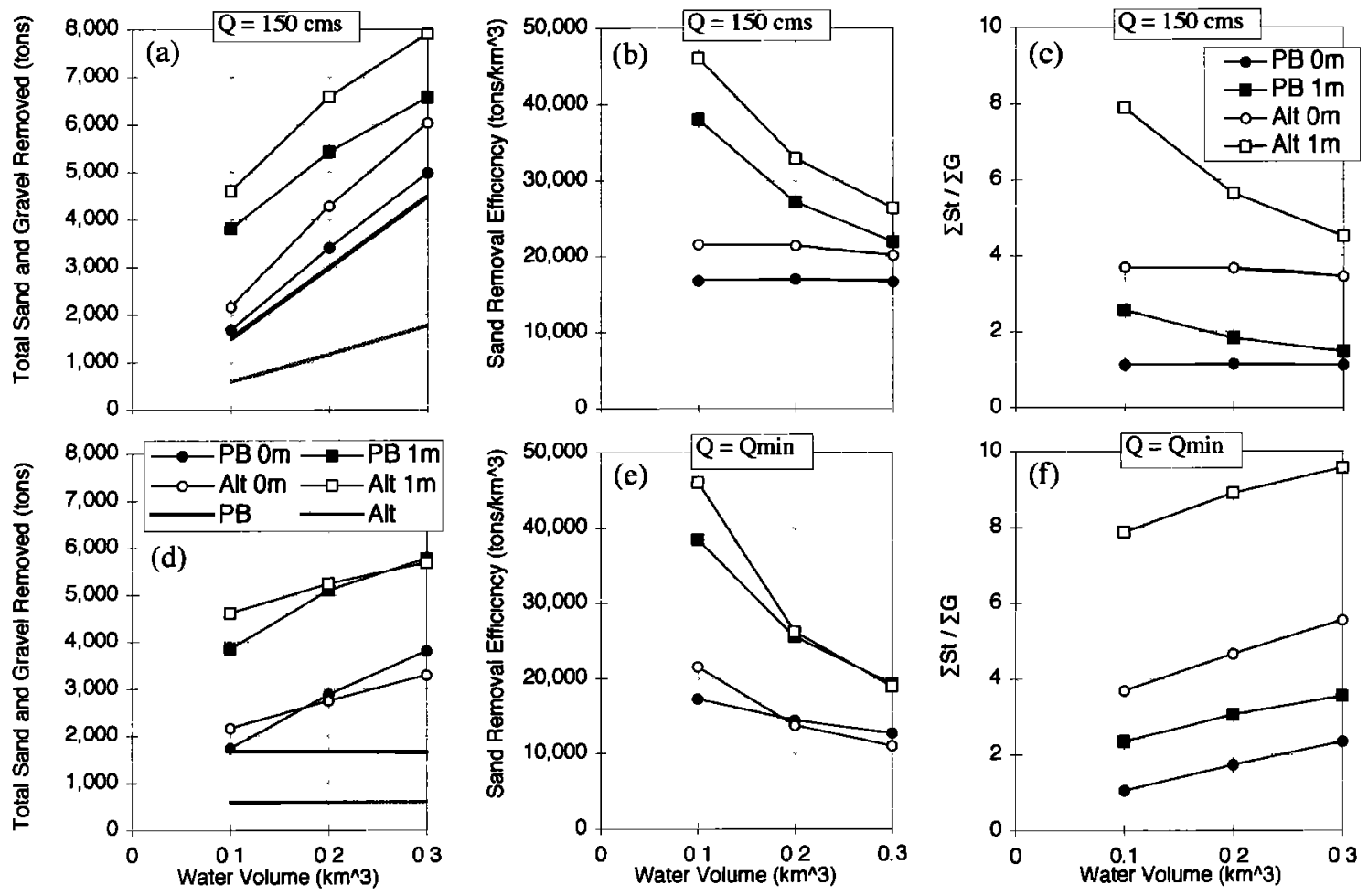

Figure 6. Total sand and gravel removed, sand removal efficiency, and ratio of sand to gravel removal, as a function of flush volume and dredge depth. Figures $6 \mathrm{a}, 6 \mathrm{~b}$, and $6 \mathrm{c}$ use constant $Q=150 \mathrm{~m}^{3} / \mathrm{s} ;$ Figures $6 \mathrm{~d}$, $6 \mathrm{e}$, and $6 \mathrm{f}$ use minimum $Q$ required for $t_{\mathrm{ex}}=1$ for the specified water volume. Sand removal efficiency calculated as tons of sand removed per cubic kilometer of water. The total volume of both sand and gravel removed increases with water volume, but sand removal efficiency decreases because $F_{\mathrm{s}}$ and pool trap efficiency decrease over a longer release. See text for further explanation.

gravel lost is constant, so the increase of sand removal with $\forall$ causes the sand/gravel removal ratio to increase with $\forall$ (Figure 6f). For $Q_{\min }<150 \mathrm{~m}^{3} / \mathrm{s}$ the total sand removed and sand removal efficiency are slightly smaller than for $Q=150 \mathrm{~m}^{3} / \mathrm{s}$, even though the ratio of sand to gravel removal is larger.

The influence of dredged pools on the downstream distribution of sand removal is shown in Figure 7 for the cases $h_{\mathrm{d}}=$ $0.0 \mathrm{~m}$ and $1.0 \mathrm{~m}$ in the existing five pools and the two pools added in the downstream half of the study reach to provide a more uniform distribution of sand removal. The case shown uses the Poker Bar rating curves and $\forall$ of $0.1,0.2$, and $0.3 \mathrm{~km}^{3}$ at $Q=150 \mathrm{~m}^{3} / \mathrm{s}$. Figures $7 \mathrm{a}-7 \mathrm{~b}$ and Figures $7 \mathrm{c}-7 \mathrm{~d}$ show the proportion of sand in the surface $F_{\mathrm{s}}$ and subsurface $F_{\mathrm{ss}}$ layers, respectively. Without pool dredging, sand removal occurs only at the downstream end of the reach, and there is a clear bottleneck effect: the decrease in sand content at the downstream end is far less for $h_{\mathrm{d}}=0$ (Figures $7 \mathrm{a}$ and $7 \mathrm{c}$ ) than for $h_{\mathrm{d}}=1.0 \mathrm{~m}$ (Figures $7 \mathrm{~b}$ and $7 \mathrm{~d}$ ). Dredged pools not only increase the total amount of sand removed but provide a more uniform distribution of sand removal. Uniform sand removal is most evident at the smallest value of $\forall$. At larger $\forall$, more extensive pool filling and diminished pool trap efficiency diminish the decrease in sand content at the downstream end. A flush volume of $0.2 \mathrm{~km}^{3}$ would be more effectively used in two separate releases with interim pool dredging to maintain the pool trap efficiency.

The alternative sediment rating curves produce a larger sand transport and smaller gravel transport than the Poker Bar curves. As a result, the alternative curves give a smaller dura- tion for the flushing flow needed to reduce the sand content in the reach and predict a more favorable ratio of sand to gravel transport. Several important conclusions are independent of the choice of sediment rating curve. Both cases point to a superior flushing discharge of moderate size, of the order of $150 \mathrm{~m}^{3} / \mathrm{s}$, in order to minimize gravel loss and maximize the amount of sand trapped in dredged pools. In both cases, the total quantity of sand removed increases with flush volume but is most efficient at smaller volumes.

\section{Conclusions}

Numerous objectives may be defined for a sediment maintenance flushing flow. Among the most important and commonly needed are to maximize the total sand removal and the ratio of sand to gravel transport, to minimize the water volume used and gravel loss, and to require a minimum amount of gravel entrainment to loosen the bed surface and entrain subsurface sand. Some of these objectives clearly conflict: a discharge cannot both minimize gravel transport and maximize sand transport; a release that is just sufficient to entrain most of the bed surface and provide some subsurface flushing will maximize neither selective transport nor sand removal efficiency. Specification of a flushing flow necessarily represents a compromise among gravel loss, sand removal, and water volume.

The options for sediment maintenance flows considered in this paper are the volume and release rate for flushing water and the number and depth of dredged pools. Artificial gravel 

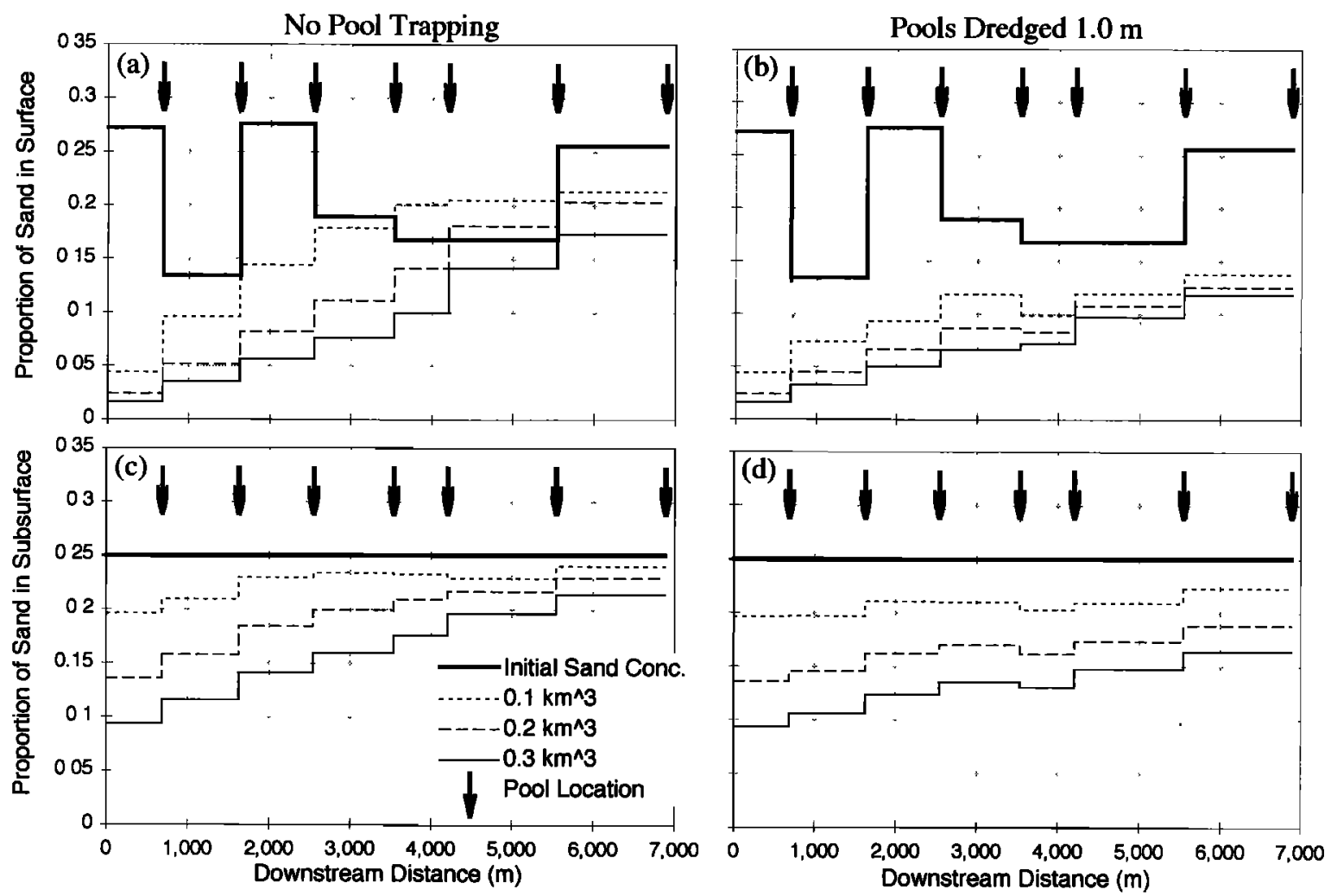

Figure 7. Along-stream distribution of sand in the bed surface and subsurface as a function of water volume and pool dredging for $Q=150 \mathrm{~m}^{3} / \mathrm{s}$. Estimates use the Poker Bar rating curves. Sand proportion in the surface and subsurface layers given in the top and bottom panels, respectively. (left) the case with no pool dredging; (right) dredging to a depth of $1 \mathrm{~m}$ below steady state depth. A strong bottleneck effect is evident for the no dredging case, for which sand removal occurs only at the downstream end.

replacement is implicitly considered by calculating the gravel loss associated with the other options. Evaluation of the tradeoffs among these options requires quantitative estimates of the gravel entrainment, gravel transport, and sand removal produced by a flushing release.

To be useful, a method for evaluating the effectiveness of different flushing options must balance system complexity with the sparse data typically available for large gravel-bed rivers. Sand and gravel transport are represented with rating curves. Approximate methods are introduced for estimating pool sediment trapping, upward supply of sand from the bed subsurface, and the rate of gravel entrainment. These are combined in a sand routing algorithm to estimate sand removal, which, together with an estimate of gravel loss, provide the basis for evaluating the cost and effectiveness of different combinations of flush volume, discharge, and pool dredging. Application of these methods is developed for the Trinity River, California.

The optimum magnitude of a sediment maintenance discharge is a compromise. Larger discharges produce more efficient sand transport and allow finer-grained sediment to be entrained from the bed subsurface but also increase the downstream loss of gravel, reduce the trap efficiency of dredged pools, and cause a larger proportion of pool storage to be filled with gravel. Smaller discharges produce favorable selective transport of fine sediment but do not produce the entrainment of the gravel surface needed to loosen the bed structure and flush sand from the subsurface.

A superior solution may be obtained if pools are dredged to act as sediment traps. Pools increase sand removal efficiency by providing multiple exits from the channel and minimize gravel loss if dredged sediment is screened and the gravel returned to the river. The location of dredged pools determines the spatial distribution of sand removal. If an even distribution of sand removal is desired, pools must be located throughout the reach.

For the Trinity River case a discharge magnitude and duration just sufficient to entrain the coarse portion of the bed surface is found to maximize sand removal by dredged pools and minimize gravel loss but at the cost of reduced sand removal magnitude and efficiency. Final specification of a flushing release must balance the relative costs of water, pool dredging, and artificial gravel replacement in the trade-off between sand removal efficiency and gravel loss. The method developed here provides a basis for this comparison.

Alternative sets of sediment rating curves were used to evaluate the sensitivity of the flushing results to the estimated sand and gravel transport rates, to which considerable uncertainty may often be assigned. The total amount of sand and gravel removed and therefore the volume of the flushing release required to reduce the sand content by a specified amount, is sensitive to the estimate of sand and gravel transport rates. Other results are less sensitive, including the observation that a flushing discharge of moderate size minimizes gravel loss, maximizes the amount of sand trapped in dredged pools, and maximizes the efficiency of sand removal.

Acknowledgments. This study was funded by the U.S. Fish and Wildlife Service (USFWS), Trinity River Flow Study, under coopera- 
tive agreements with the Johns Hopkins University (14-16-0001-91514) and the University of California (14-16-0001-91515), the latter administered by the Center for Environmental Design Research. Additional funding was provided by the Southern California Edison Company and by an award for Research Excellence from the Pacific Gas and Electric Company administered by the University of California Center for Water and Wildland Resources. The development of the methods presented here benefited from discussions with Andy Hamilton, Mark Hampton, Scott McBain, John Pitlick, and Bill Trush. The USFWS office in Weaverville provided useful information for our study, as did the Trinity Restoration Associates in Arcata, California. Review comments by Roger Kuhnle and Tom Lisle improved the clarity and accuracy of the text.

\section{References}

Andrews, E. D., Effective and bankfull discharges of streams in the Yampa River basin, Colorado and Wyoming, J. Hydrol., 46, 311-330, 1980.

Ashida, K., and S. Egashira, Mechanisms of armoring phenomena, paper presented at Seminar 4, Armoring and Grain Sorting, 23rd International Association for Hydraulic Research Congress, Ottawa, Canada, 1989.

Beschta, R. L., and W. L. Jackson. The intrusion of fine sediments into a stable gravel bed, J. Fish. Res. Board Can., 36, 204-210, 1979.

Carling, P., The concept of dominant discharge applied to two gravelbed streams in relation to channel stability thresholds, Earth Surf. Processes Landforms, 13, 355-367, 1988.

Carson, M. A., and G. A. Griffiths, Bedload transport in gravel channels, J. Hydrol. N. Z., 26(1), 1-151, 1987.

Church, M., J. F. Wolcott, and W. K. Fletcher, A test of equal mobility in fluvial sediment transport: behavior of the sand fraction, Water Resour. Res., 27, 2941-2951, 1991.

Diplas, P., and G. Parker, Pollution of gravel spawning grounds due to fine sediment, Proj. Rep. 240, St. Anthony Falls Hydraul. Lab., Univ. of Minn., Minneapolis, 1985.

Frederiksen, Kamine, and Associates, Proposed Trinity River basin fish and wildlife management program, Appendix B, Sediment and related analysis, report prepared for the U.S. Department of Interior Water and Power Resources Service, Sacramento, Calif., 1980.

Hill, M. T., W. S. Platts, and R. L. Beschta, Ecological and geomorphologic concepts for instream and out-of-channel flow requirements, Rivers, 2, 198-210, 1991.

Hirano, M., River bed degradation with armoring, Proc. Jpn. Soc. Civ. Eng., 195, 55-65, 1971.

Holly, F. M., and J.-L. Rahuel, New numerical/physical framework for mobile-bed armoring, 1, Numerical and physical principles, J. Hydraul. Res., 28(4), 401-415, 1990.

Jackson, W. L., and R. L. Beschta, A model of two-phase bedload transport in an Oregon coast range stream, Earth Surf. Processes Landforms, 9, 517-527, 1982.

Kondolf, G. M., and P. R. Wilcock, The flushing flow problem: Defining and evaluating objectives, Water Resour. Res., 32, 2589-2599, 1996.

Kuhnle, R. A., Fractional transport rates of bedload on Goodwin Creek, in Dynamics of Gravel-Bed Rivers, edited by P. Billi, R. D.
Hey, C. R. Thorne, and P. Tacconi, pp. 141-155, John Wiley, New York, 1992.

Leopold, L. B., Sediment size that determines channel morphology, in Dynamics of Gravel-Bed Rivers, edited by P. Billi, R. D. Hey, C. R. Thorne, and P. Tacconi, pp. 297-311, John Wiley, New York, 1992.

Leopold, L. B., M. G. Wolman, and J. P. Miller, Fluvial Processes in Geomorphology, W. H. Freeman, New York, 1964.

Ligon, F. K., W. E. Dietrich, and W. J. Trush, Downstream ecological effects of dams, a geomorphic perspective, Bioscience, 45(3), 183$192,1995$.

Lisle, T. E., Particle size variations between bed load and bed material in natural gravel bed channels, Water Resour. Res., 31, 1107-1118, 1995.

Milhous, R. T., Effect of sediment transport and flow regulation on the ecology of gravel bed rivers, in Gravel-Bed Rivers, edited by R. D. Hey, J. C. Bathurst, and C. R. Thorne, pp. 819-841, John Wiley, New York, 1982.

Milhous, R. T., Calculation of flushing flows for gravel and cobble bed rivers, in Hydraulic Engineering, vol. 1, Proceedings of the $1990 \mathrm{Na}$ tional Conference, edited by H. H. Chang and J. C. Hill, pp. 598-603, Am. Soc. of Civ. Eng., New York, 1990.

Parker, G., and A. J. Sutherland, Fluvial armor, J. Hydraul. Res., 28(5), 529-544, 1990.

Reiser, D. W., M. P. Ramey, and T. A. Wesche, Flushing flows, in Alternatives in Regulated River Management, edited by J. A. Gore and G. E. Petts, pp. 91-135, CRC Press, Boca Raton, Fla., 1989.

Wathen, S. J., R. I. Ferguson, T. B. Hoey, and A. Werrity, Unequal mobility of gravel and sand in weakly bimodal river sediments, Water Resour. Res., 31, 2087-2096, 1995.

Wilcock, P. R., Sediment maintenance flows: Feasibility and basis for prescription, paper presented at the Fourth Gravel-Bed Rivers Workshop, U.S. Fish and Wildlife Serv., Oreg. State Univ., Gold Bar, Wash., Aug. 1995.

Wilcock, P. R., G. M. Kondolf, A. F. Barta, W. V. G. Matthews, and C. C. Shea, Spawning gravel flushing during trial reservoir releases on the Trinity River: Field observations and recommendations for sediment maintenance flushing flows, final report submitted to U.S. Fish and Wildlife Serv. Trinity River Flow Study, 222 pp., Lewiston, Calif., Feb. 1995.

Wilcock, P. R., A. F. Barta, C. C. Shea, G. M. Kondolf, W. V. G. Matthews, and J. C. Pitlick, Observations of flow and sediment entrainment on a large gravel-bed river, Water Resour. Res., this issue.

A. F. Barta, Intermountain Research Station, U.S. Forest Service, 316 E. Myrtle St., Boise, ID 83702. (e-mail: sediment@micron.net)

G. M. Kondolf and W. Y. G. Matthews, Center for Environmental Design Research, University of California, 390 Wurster Hall, Berkeley, CA 94720. (e-mail: kondolf@ced.berkeley.edu)

P. R. Wilcock, Department of Geography and Environmental Engineering, The Johns Hopkins University, Baltimore, MD 21218. (e-mail: wilcock@jhu.ms.hcf.jhu.edu)

(Received February 5, 1996; revised May 20, 1996; accepted May 24, 1996.) 